\title{
Differences in the Expression of Protein Kinase C Isoforms and Its Translocation After Stimulation With Phorbol Ester Between Young-Adult and Middle-Aged Ventricular Cardiomyocytes Isolated From Fischer 344 Rats
}

\author{
Michiyo Takayama, MD; Yoshinori Ebihara, MD; Masato Tani, MD
}

\begin{abstract}
It is known that the tolerance against ischemia-reperfusion and the effects of preconditioning decrease in aged hearts, but the mechanisms responsible for this diminished ischemic tolerance and reduced efficacy of preconditioning remain unknown. To determine the age-related changes in these mechanisms, protein kinase $\mathrm{C}$ (PKC) isoform expression and its translocation by phorbol ester were analyzed because $\mathrm{PKC}$ is believed to be involved in preconditioning. Immunoblotting and immunostaining analysis were performed with isoform-specific PKC antibodies using cardiomyocytes isolated from young-adult (12-week-old: $12 \mathrm{~W})$ and middle-aged (50-week-old: $50 \mathrm{~W}$ ) Fischer 344 rats. There was significantly greater PKC $\delta$ expression in both the cytosolic and membrane fractions of $12 \mathrm{~W}$ cardiomyocytes than in $50 \mathrm{~W}$ ones. Exposure of cardiomyocytes to $100 \mathrm{nmol} / \mathrm{L} 4 \beta$-phorbol 12 myristate 13-acetate (PMA) caused translocation of PKC $\delta$ from the cytosol to the membrane in the $12 \mathrm{~W}$ group, whereas in the $50 \mathrm{~W}$ group, the translocation was attenuated. Immunostaining confirmed the PKC $\delta$ translocation in the $12 \mathrm{~W}$ cardiomyocytes. Oil pellet examination showed that the translocation of PKC $\delta$ induced by preconditioning was associated with cell protection from ischemic injury in the $12 \mathrm{~W}$ group only. Age-related changes in PKC isoform expression and activation in cardiomyocytes might be responsible for the reduced ischemic tolerance and less efficient preconditioning that accompanies aging. (Jpn Circ J 2001; 65: 1071-1076)
\end{abstract}

Key Words: Aging; Myocytes; Phorbol ester; Preconditioning; Protein kinase C

$\mathbf{T}$ he increasing size of the elderly population is having an impact on geriatric medicine, resulting in a greater number of elderly patients suffering from ischemic heart disease (IHD). Clinical studies reveal that the prognosis for elderly patients with IHD is poorer because of the morphologic and functional changes in the cardiovascular system that occur with aging! ${ }^{-4}$ Specifically, an increase in the myocardial collagen content and its cross-linking, as well as amyloid deposition, leads to increased myocardial stiffness, and 'drop-out' of myocytes, tubular dilation, lipid deposition, and the appearance of lipofuscin granules account for the degenerative changes in the myocardium? These changes may explain why the senescent heart is less able to respond to acute hemodynamic challenges. Other comorbid conditions, including cerebrovascular and peripheral vascular diseases and renal insufficiency, are also more common in older patients and may limit therapeutic procedures, resulting in a poorer prognosis. However, at the cellular level, neither the mechanisms of ischemic tolerance nor their age-related changes, which might regulate the ability of cardiomyocytes to tolerate ischemia-reperfusion, have been determined. In the clinical field, people who suffer from IHD are usually

(Received May 9, 2001; revised manuscript received August 27, 2001; accepted September 11, 2001)

Division of Geriatric Medicine, Department of Internal Medicine, Keio University School of Medicine, Tokyo, Japan

Mailing address: Michiyo Takayama, MD, Division of Geriatric Medicine, Department of Internal Medicine, Keio University School of Medicine, 35 Shinanomachi, Shinjuku-ku, Tokyo 160-8582, Japan. E-mail: michiyo@sc.keio.ac.jp middle aged or older and therefore if the mechanisms of ischemic tolerance change with age, we need a new strategy against ischemia-reperfusion injury for the elderly.

Classically, a series of brief coronary occlusions, each separated by a brief period of reperfusion (ischemic preconditioning; PC), makes the heart better able to withstand a subsequent longer ischemic insult? Previous studies have confirmed that certain drugs or exposure to hypoxia also have a protective effect similar to PC 6,7 Furthermore, PC can be blocked by protein kinase $\mathrm{C}(\mathrm{PKC})$ inhibitors and/or simulated by direct activation of PKC using diacylglycerol or phorbol ester analogues?-12 Based on these results, PKC is believed to play an important role in the PC signaling cascade in cardiomyocytes.

The effects of aging on the ability to tolerate ischemia or PC have been studied in aged rat hearts: the ischemic tolerance of the myocardium decreases and the cardioprotective effects of PC not only diminish with age, but PC actually worsens the myocardial injury! ${ }^{13-15}$ In the present study, we hypothesized that the activity of PKC decreased with age in rat cardiomyocytes, causing diminished PC effects in old rat hearts. To test this hypothesis, we determined the agerelated changes in PKC isoform expression and the translocation of PKC using phorbol ester, one of the potent PKC activators, in isolated rat ventricular cardiomyocytes.

\section{Methods}

Animals

The experiments were carried out using hearts from male Fischer 344 rats, a strain that has been used extensively as a 
model of aging. The animals were maintained in the Animal Care Facility of Keio University School of Medicine and this investigation conformed to the principles outlined in the Guide for the Care and Use of Laboratory Animals published by the Keio animal care committee (Keio University School of Medicine, Tokyo, Japan).

\section{Heart Perfusions and Myocyte Isolations}

The preparation used in this study has been described previously ${ }^{16}$ In brief, following the intraperitoneal injection of sodium pentobarbital $(40 \mathrm{mg} / \mathrm{kg})$, hearts were removed from young-adult (12-week-old: $12 \mathrm{~W}, \mathrm{n}=12)$ and middleaged (50-week-old: $50 \mathrm{~W}, \mathrm{n}=8$ ) rats. The excised heart was perfused for $5 \mathrm{~min}$ using a modified non-recirculating Langendorff technique with $\mathrm{Ca}^{2+}$-free buffer (Buffer A) containing (in mmol/L) $134 \mathrm{NaCl}, 5.4 \mathrm{KCl}, 10$ HEPES, 10 glucose, $1 \mathrm{MgCl}_{2}, 0.33 \mathrm{NaH}_{2} \mathrm{PO}_{4}(\mathrm{pH} 7.4)$. The coronary perfusion flow rate was set at $10 \mathrm{ml} / \mathrm{min}$. The buffer was gassed with $100 \%$ oxygen and the entire perfusion system was maintained at $37^{\circ} \mathrm{C}$.

To isolate ventricular myocytes, the perfusion buffer was changed to Buffer A containing $300 \mathrm{U} / \mathrm{ml}$ collagenase (type 2, Worthington Biochemical, Lakewood, CA, USA), $0.1 \mathrm{mg} / \mathrm{ml}$ protease (type 1, Sigma Chemical, St Louis, $\mathrm{MO}$, USA), and $0.04 \mathrm{mmol} / \mathrm{L} \mathrm{CaCl}_{2}$, and the hearts were perfused for $20 \mathrm{~min}$ in a recirculating manner. The heart was removed from the perfusion cannula and the atrial tissue was excluded. Ventricular tissue was minced with scissors in $15 \mathrm{ml}$ of Buffer A containing $0.2 \mathrm{mmol} / \mathrm{L} \mathrm{CaCl}$, incubated at $37^{\circ} \mathrm{C}$ for $15 \mathrm{~min}$ in a shaking bath $(30 \mathrm{~Hz})$, and then filtered through a 210-mesh nylon screen. The supernatant buffer was aspirated off and the cells were resuspended in $20 \mathrm{ml}$ of Buffer A containing $0.5 \mathrm{mmol} / \mathrm{L} \mathrm{CaCl} 2$ for $10 \mathrm{~min}$. The final cell pellet was suspended in Buffer A containing $1.0 \mathrm{mmol} / \mathrm{L} \mathrm{CaCl}$. Myocytes were used only when there were more than $80 \%$ of rod-shaped cells.

\section{Preparation of Cytosolic and Membrane Fractions}

Myocytes from each age heart were divided into 2 groups. One group $(\mathrm{n}=6$ for $12 \mathrm{~W}, \mathrm{n}=4$ for $50 \mathrm{~W})$ was incubated with $100 \mathrm{nmol} / \mathrm{L} 4 \beta$-phorbol 12 -myristate 13 -acetate (PMA) for $10 \mathrm{~min}$ at room temperature, and the other group ( $\mathrm{n}=6$ for $12 \mathrm{~W}, \mathrm{n}=4$ for $50 \mathrm{~W}$ ) was incubated without PMA and served as a control group.

Cell pellets were resuspended in ice-cold separation buffer containing (in $\mathrm{mmol} / \mathrm{L}$ ) 20 HEPES, 250 sucrose, 2 EDTA, 2 EGTA, and $10 \beta$-mercaptoethanol (pH 7.5). Cells were homogenized with leupeptin $(\sim 1 \mathrm{mmol} / \mathrm{L})$ and phenylmethanesulfonyl fluoride (Pmsf, $\sim 1 \mathrm{mmol} / \mathrm{L}$ ) using a sonicator (Ultrasonic Processor GE50, EYELA, Tokyo, Japan). The homogenate was centrifuged at $100,000 \mathrm{G}$ for $40 \mathrm{~min}$, and the supernatant was designated as the cytosolic fraction (c). The pellet was resuspended in separation buffer containing $0.5 \%$ (vol $/ \mathrm{vol}$ ) Triton-X, leupeptin, and Pmsf, followed by centrifugation at $100,000 \mathrm{G}$ for $40 \mathrm{~min}$ and the resultant supernatant represented the membrane fraction $(\mathrm{m})$.

\section{Western Blot Analysis of PKC Isoforms}

Twenty micrograms each of the cytosolic and membrane proteins were analyzed by one-dimensional electrophoresis on $10 \%(\mathrm{wt} / \mathrm{vol})$ SDS-polyacrylamide gels. The gels were transferred to nitrocellulose membranes at $400 \mathrm{~mA}$ for 3.5 h. Blots were blocked overnight with $5 \%(\mathrm{wt} / \mathrm{vol})$ skim milk at room temperature before they were incubated for $2.5 \mathrm{~h}$ with one of the primary antibodies (anti-PKCa, $\beta \mathrm{ll}$, $\delta$, or $€$; dilution, 1:1,000; rabbit polyclonal $\mathrm{IgG}$, Santa Cruz Biotechnology, Santa Cruz, CA, USA) in the blotting buffer containing (in mmol/L) $137 \mathrm{NaCl}, 20$ Tris base, and $0.2 \%$ (vol/vol) Tween 20 (pH 7.6). After incubation with a primary antibody, blots were exposed for $1 \mathrm{~h}$ at room temperature to a peroxidase-conjugated secondary antibody (dilution, 1:5,000; anti-rabbit IgG, Amersham International, Buckinghamshire, UK). Membranes were rinsed 3 times with phosphate buffered saline (PBS)-Tween20 and finally developed with the enhanced chemiluminescence Western blotting system (ECL, Amersham). AttoPhos (Amersham) was used to identify each PKC isoform on the blot. Cytosolic- and membrane-associated PKC bands were quantified using an optical densitometer (ImageQuaNT FluorImager 595, Molecular Dynamics, Sunnyvale, CA, USA).

To assess the PKC translocation stimulated by PMA, the membrane-cytosol ratio $(\mathrm{m} / \mathrm{c})$ was calculated as the band density for the membrane fraction divided by the band density for the cytosolic fraction.

\section{Immunostaining}

Ventricular cells were isolated as described before. The PMA stimulation protocol for myocytes was similar to that used for the immunoblot analysis. Immediately after incubation with/without PMA, the cells were sedimented onto 12-mm glass coverslips coated with laminin. Excess buffer was removed and replaced by a solution containing $4 \%$ formaldehyde dissolved in PBS containing (in mmol/L) 145 $\mathrm{NaCl}, 8 \mathrm{Na}_{2} \mathrm{HPO}_{4} \cdot 12 \mathrm{H}_{2} \mathrm{O}$, and $2 \mathrm{NaH}_{2} \mathrm{PO}_{4} \cdot 2 \mathrm{H}_{2} \mathrm{O}(\mathrm{pH} 7.4)$, and incubated overnight at $37^{\circ} \mathrm{C}$ to fix the cells. Cells were subsequently washed 3 times with PBS. Nonspecific binding was blocked for $1 \mathrm{~h}$ incubation at room temperature with PBS containing 5\% (wt/vol) normal blocking serum (Santa Cruz Biotechnology). Coverslips were then incubated with one of the anti-PKCa, $\beta$ ll, $\delta$, or $\epsilon$ primary antibodies dissolved in PBS-blocking serum $(1 \mu \mathrm{g} / \mathrm{ml})$ overnight at $4^{\circ} \mathrm{C}$. Cells were then incubated with biotinylated secondary antibody solution for $30 \mathrm{~min}$, followed by incubation with Avidin Biotin (AB) Enzyme Reagent for $30 \mathrm{~min}$ at room temperature. Cells were washed with $1 \%$ ( $\mathrm{vol} / \mathrm{vol}$ ) Triton X-100 in PBS, rinsed with distilled water, and dried. DAB staining solution (Santa Cruz Immunoperoxidase Staining Kit, Santa Cruz Biotechnology) was added to cells for 5-10 min, and rinsed with distilled water. After staining, mounting medium and coverslips were placed on the cells, and the stained cells were analyzed by light microscopy. To assess translocation of the PKC isoforms to the membrane, myocytes were scanned along their short axis and density profiles were obtained.

\section{Oil Pellet Examination}

Myocytes isolated from each age group were subjected to simulated ischemia under oil shield buffer for $120 \mathrm{~min}$ (Oil+) in a microtube at room temperature. After $120 \mathrm{~min}$ of simulated ischemia or oxygenated incubation (Oil-), cells were stained on a slideglass with trypan blue and the percentage of the stained cells in a total of 300 cells were counted as an index of ischemic injury. Before the $120 \mathrm{~min}-$ simulated ischemia, PC was induced by $10 \mathrm{~min}$ of oil pelleting incubation followed by oxygenated incubation for 15 min (Oil-PC). To determine which PKC-isoform was associated with PC, Western blot analysis was done as described before using Oil-PC myocytes just before undergoing 120-min simulated ischemia. 
A PKC- $\alpha$

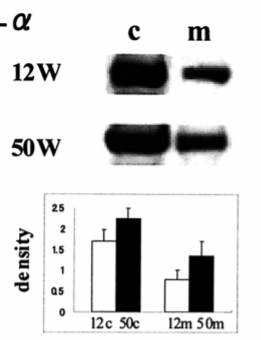

C PKC- $\delta$

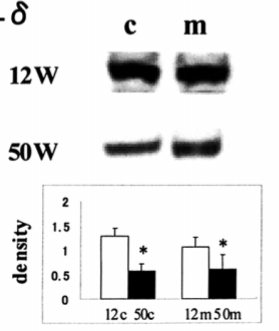

B PKC- $\beta$ II

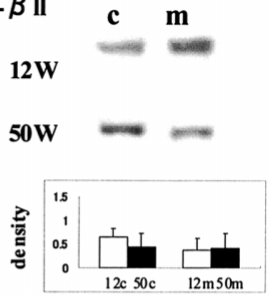

D PKC- $\varepsilon$

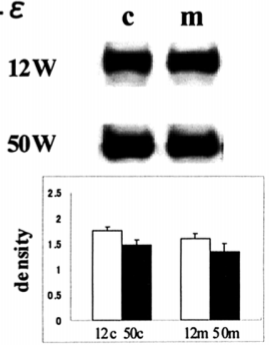

Fig 1. Expression of protein kinase $\mathrm{C}(\mathrm{PKC})$ isoforms in the cytosolic and membrane fractions of ventricular cardiomyocytes determined by immunoblotting. PKC $\delta$ bands significantly decreased in 50 -weekold $(50 \mathrm{~W})$ myocytes compared with 12-week-old $(12 \mathrm{~W})$ ones in both the cytosolic and membrane fractions. Values are reported as mean \pm $\mathrm{SE}(\mathrm{n}=6$ for $12 \mathrm{~W}, \mathrm{n}=4$ for $50 \mathrm{~W}) .12 \mathrm{c}$ : cytosolic fraction of the $12 \mathrm{~W}$ group; $12 \mathrm{~m}$ : membrane fraction of the $12 \mathrm{~W}$ group; $50 \mathrm{c}$ : cytosolic fraction of the $50 \mathrm{~W}$ group; $50 \mathrm{~m}$ : membrane fraction of the $50 \mathrm{~W}$ group. ${ }^{*} \mathrm{p}<0.05$ vs $12 \mathrm{~W}$.

$12 \mathrm{~W}$ control

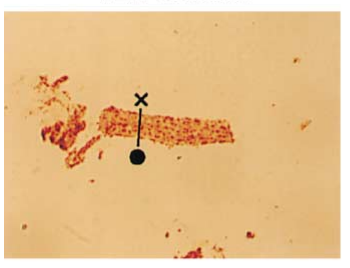

$\overleftrightarrow{25 \mu \mathrm{m}}$

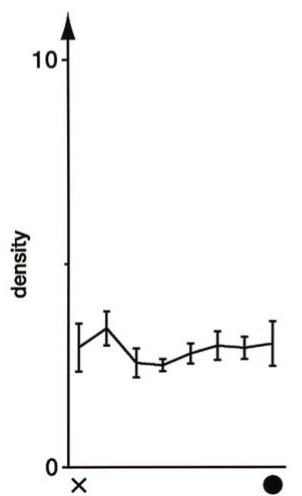

12 with PMA

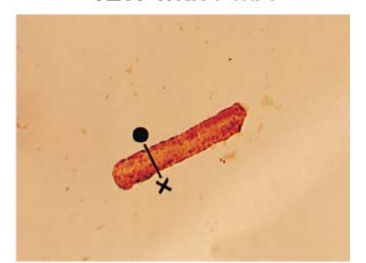

$\overleftrightarrow{25 \mu \mathrm{m}}$

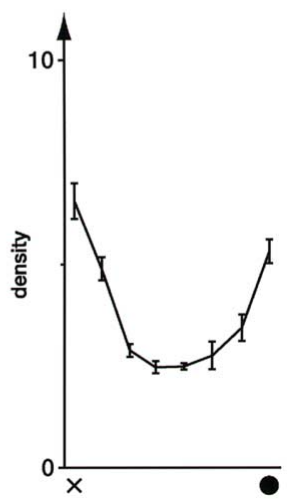

Fig 3. The density profiles of immunocytochemical staining for protein kinase C (PKC) $\delta$ in 12-week-old ventricular cardiomyocytes. The surface-to-cytosol staining ratio dramatically increased in PMA-stimulated cells. The lower panels show the density profiles of staining (arbitrary units) along the short axis of the myocytes shown in the upper panels. In the PMA-stimulated cell, the density was higher on both sides of the myocyte, indicating that PKC $\delta$ translocated to the cell membrane following PMA stimulation. Values are reported as mean $\pm \operatorname{SE}(n=6)$ in the lower panels.

A PKC- $\alpha$

$12 \mathrm{~W}$

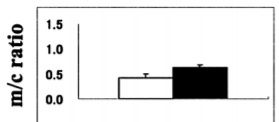

50W

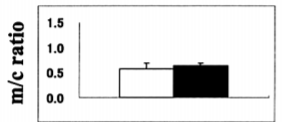

C PKC- $\delta$

$12 \mathrm{~W}$

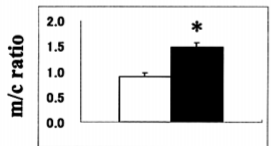

50W

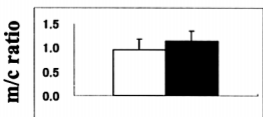

B PKC- $\beta$ II

$12 \mathrm{~W}$

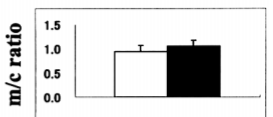

50W

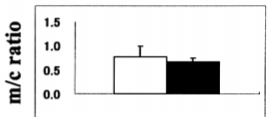

D PKC- $\varepsilon$

12W

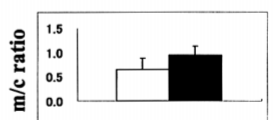

50W

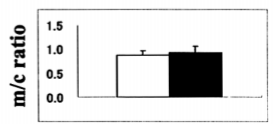

Fig 2. Translocation of protein kinase $\mathrm{C}(\mathrm{PKC})$ isoforms by stimulation with $4 \beta$-phorbol 12-myristate 13 -acetate (PMA). The relative degree of each isoform translocation was assessed by the ' $\mathrm{m} / \mathrm{c}$ ratio' (the ratio of density of the membrane fraction to that of the cytosolic fraction). In 12-week-old myocytes, only the $\mathrm{m} / \mathrm{c}$ ratio of $\mathrm{PKC} \delta$ increased significantly in the presence of PMA compared with controls (C). In 50-week-old myocytes, there were no significant changes in the $\mathrm{m} / \mathrm{c}$ ratio of each isoform, implying that none of the PKC isoforms translocated after stimulation with PMA (A-D). Values are reported as mean $\pm \mathrm{SE}(\mathrm{n}=6$ for $12 \mathrm{~W}, \mathrm{n}=4$ for $50 \mathrm{~W})$. ( $\square$ ) control group; ( $\mathbf{\square})$ PMA group. *p $<0.05$ vs control.
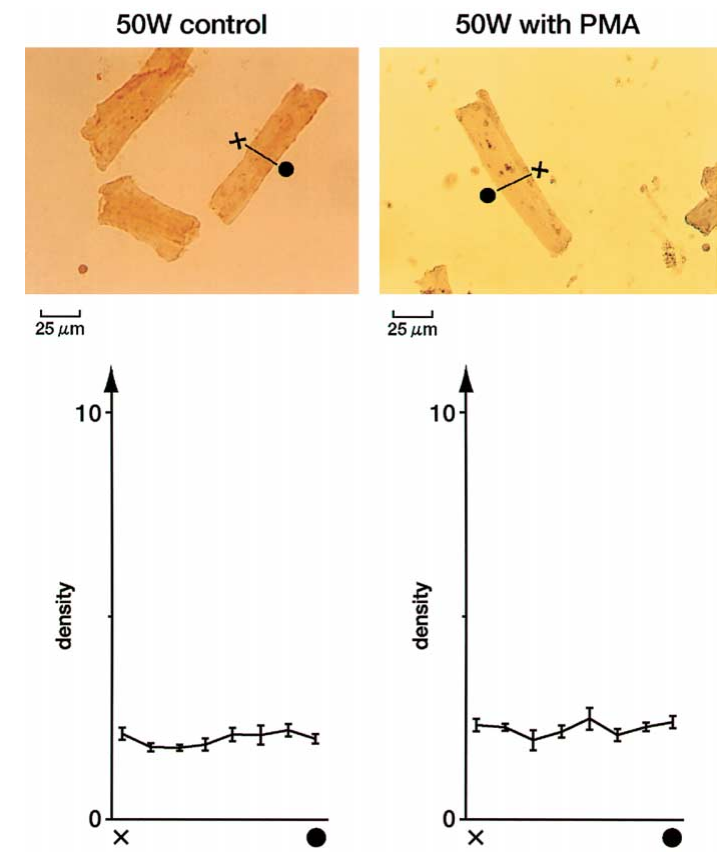

Fig 4. The density profiles of immunocytochemical staining for protein kinase C (PKC) $\delta$ in 50-week-old ventricular cardiomyocytes. There were no significant differences in the localization of immunoreactive PKC $\delta$ between control myocytes and PMA-stimulated cells. The density profiles in the lower panels show that there is no characteristic staining pattern in myocytes, irrespective of their exposure to PMA. Values are reported as mean $\pm S E(n=4)$ in the lower panels. 


\section{Chemicals}

Chemicals were obtained from Wako Chemicals (Osaka, Japan), Nakarai Chemicals (Kyoto, Japan), Sigma Chemical Co (St Louis, MO, USA), or Pharmacia Biotechnology (Uppsala, Sweden).

\section{Statistical Analysis}

Data are represented as mean \pm SE of 4-6 experiments. Comparisons between 2 groups were analyzed by unpaired Student's t-test. Differences between groups were determined by one-way ANOVA followed by Fisher's protected
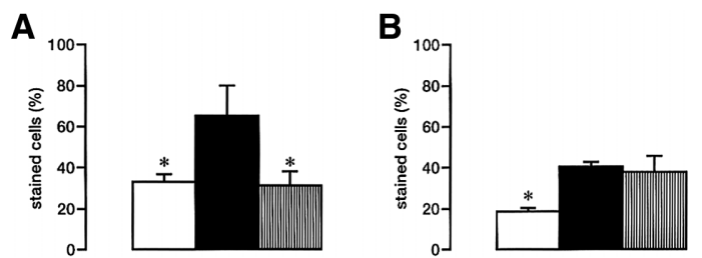

Fig 5. The percentage of stained myocytes with trypan blue, as an index of ischemic injury, in oil pellet examination. In 12-week-old myocytes, the percentage of stained cells was significantly less in the Oil-PC group than in the Oil+ group (A). In 50-week-old myocytes, there were no significant changes between the Oil-PC and Oil+ groups (B). Values are reported as mean $\pm \mathrm{SE}(\mathrm{n}=4$ for each age). ( $\square$ ) Oil- group; (ם) Oil+ group; (四) Oil-PC group. ${ }^{*} \mathrm{p}<0.05$ vs Oil+.
A

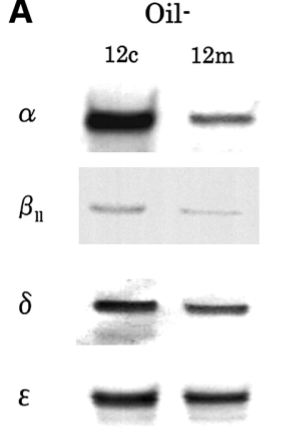

B

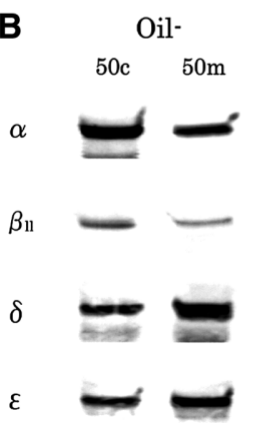

Oil-PC

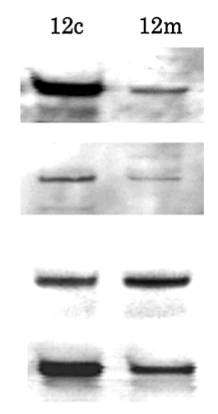

Oil-PC

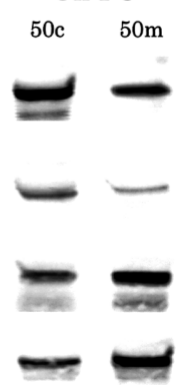

Fig 6. Western blot analysis of protein kinase $\mathrm{C}(\mathrm{PKC})$ isoforms in oil pellet examination. In 12-week-old (12W) myocytes, the band density of PKC $\delta$ of the membrane fraction was stronger than that of the cytosolic fraction in the Oil-PC group compared with the Oilgroup, but the other PKC-isoform bands showed no change, indicating that only PKC $\delta$ translocated to the membrane fraction after oil pellet preconditioning (A). In 50-week-old (50W) myocytes, the bands of each PKC-isoform expressed similar density (B). 12c: cytosolic fraction of the $12 \mathrm{~W}$ group; $12 \mathrm{~m}$ : membrane fraction of the $12 \mathrm{~W}$ group; 50c: cytosolic fraction of the $50 \mathrm{~W}$ group; $50 \mathrm{~m}$ : membrane fraction of the $50 \mathrm{~W}$ group. least significant difference test. A p value of less than 0.05 was considered statistically significant.

\section{Results}

\section{PKC Isoform Expression in $12 \mathrm{~W}$ or $50 \mathrm{~W}$ Control Cardiomyocytes}

As shown in Fig 1A, B and D, the density (arbitrary units) of the PKCa, $\beta$ 1l, and $€$ bands for both the cytosolic and membrane fractions was similar in the $12 \mathrm{~W}$ and $50 \mathrm{~W}$ control cardiomyocytes, although the PKCa of both fractions appeared to be greater in the older rat cardiomyocytes (Fig 1A). However, the PKC $\delta$ was significantly lower in the older control myocytes for both the cytosolic and membrane fractions (Fig 1C).

\section{Translocation of PKC Isoforms in Rat Cardiomyocytes Stimulated With PMA}

After exposure to PMA $(100 \mathrm{nmol} / \mathrm{L})$ the PKCa, $\beta$ ll, or $\epsilon$ content was the same for the $12 \mathrm{~W}$ and $50 \mathrm{~W}$ cardiomyocytes. In contrast, the expression of PKC $\delta$ was lower in the $50 \mathrm{~W}$ group compared with the $12 \mathrm{~W}$ group (data not shown). In the $12 \mathrm{~W}$ myocytes, only the $\mathrm{m} / \mathrm{c}$ ratio for PKC$\delta$ increased significantly in the presence of PMA compared with control incubations (Fig 2C). This suggests that only PKC $\delta$ translocated from the cytosolic fraction to the membrane fraction during PMA stimulation. Although the $\mathrm{m} / \mathrm{c}$ ratio for $\mathrm{PKCa}$ in the $12 \mathrm{~W}$ myocytes tended to increase after PMA treatment, the change was not significant $(\mathrm{p}=0.16)(\mathrm{Fig} 2 \mathrm{~A})$. There were no significant changes in the $\mathrm{m} / \mathrm{c}$ ratio for any of the PKC isoforms in the $50 \mathrm{~W}$ cells, suggesting that the PKC isoforms did not translocate after stimulation with PMA in the older rats (Fig 2A-D).

\section{Immunostaining Studies}

Immunocytochemical analysis was performed to confirm PKC $\delta$ translocation from the cytosolic fraction to the membrane fraction in PMA-stimulated young (12W) myocytes (Fig 3, upper panel). In contrast, immunocytochemical staining showed no significant changes in the cellular staining pattern in the older $(50 \mathrm{~W})$ myocytes after PMA stimulation (Fig 4, upper panel). The density profiles demonstrated that staining was diffuse in control cardiomyocytes of both ages, but that staining became gradually more intense from the center to the periphery of $12 \mathrm{~W}$ cardiomyocytes stimulated with PMA (Figs 3, 4, lower panels).

\section{Oil Pellet Examination}

In younger myocytes, the percentage of stained cells was significantly less in Oil-PC than Oil+ cells $(33.3 \pm 7.2 \%$ vs $65.5 \pm 14.7 \%$, respectively; $\mathrm{p}<0.05$ ) (Fig $5 \mathrm{~A}$ ), and the beneficial effect of Oil-PC was lost in the older ones (Fig 5B). Western blot analysis showed that only PKC $\delta$ translocated from the cytosol to the membrane after Oil-PC in the younger myocytes (Fig 6A); in the older myocytes, none of the PKC-isoforms translocated (Fig 6B).

\section{Discussion}

In the present study, we demonstrated that PKC $\delta$ expression decreases in both the cytosolic and membrane fractions of ventricular cardiomyocytes isolated from older rats. We also showed that the PKC $\delta$ translocation from the cytosol to membrane caused by a PKC stimulator dimin- 
ishes with aging, and that the relationship between PKC $\delta$ translocation and PC seen in the young rat ventricular cardiomyocytes is lost in the older ones.

\section{Changes in PKC Isoform Expression With Aging}

Changes in the expression of PKC isoforms in the heart during development have been demonstrated in a number of studies using chromatographic separation, immunoblotting, or immunocytochemistry, but different conclusions have been reached ${ }^{17}$ most likely because of different preparations of hearts (whole hearts, dispersed myocytes, or cultured myocytes), different strains of animals, different stages of development (fetus, neonate, or adult), and technical differences. However, based on those results, it is widely accepted that $\mathrm{PKCa}, \delta, \epsilon$, and $\zeta$ are present in adult rat isolated cardiomyocytes ${ }^{18-22}$ We demonstrated in preliminary experiments that PKCa, $\delta$, and $€$ are the dominant isoforms in isolated cardiomyocytes from both young-adult and middle-aged rats, although a small amount of PKC $\beta 11$ is also present. Therefore, we used these 4 isoforms to investigate the age-related changes in PKC isoform expression in the present study, which demonstrated that only PKC $\delta$ decreased in older cardiomyocytes.

Rybin et al investigated age-dependent differences in PKC isoform expression in extracts from the fetal (14-dayold), neonatal (2-15-day-old), and adult rat whole heart, as well as in cultured neonatal and isolated adult rat ventricular myocytes, and reported that PKCa was present in both fetal and neonatal myocytes, but not in adult myocytes? ${ }^{23}$ PKC $a$ was not detected in the adult cardiomyocytes probably because of inappropriate immunologic technique (ie, the lack of sensitivity and specificity of the antisera ${ }^{24}$ ). PKC $\delta$ was present in a greater amount in the fetal and neonatal myocytes than in adult myocardial extracts. PKC€ was present in all cell preparations, but in greatest abundance in the extracts from neonatal myocytes. Additionally, PKCa, $\delta$, and $€$ translocated from a soluble fraction to a particulate fraction in response to stimulation with phorbol ester. They hypothesized that sympathetic innervation might regulate PKC isoform expression during development. Although they did not examine middle-aged myocytes, the age-dependent decline in PKC $\delta$ content is consistent with our results.

Our studies also demonstrated an additional feature that PKC $\delta$ translocation in response to PMA was impaired in older rats. Another report demonstrated that PKC $\beta$ immunoreactivity in liver activated by heat shock diminished in aged rats (96-week-old) compared with young (8-weekold) rats ${ }^{25}$ Pucéat et al studied the differences in the expression and regulation of PKC isoforms during development using immunoblotting in neonatal (1-2-day-old) and adult (200-250 g, age not described) isolated rat cardiomyocytes; they detected PKCa, $\delta$, and $\epsilon$ in both neonatal and adult cardiomyocytes, and $\mathrm{PKC} \zeta$ was detected in greater abundance in neonatal cells. Furthermore, the responses to several agonists (phenylephrine, ATP, PMA, endothelin, and carbachol) were different for each PKC isoform 19 These results suggest that the regulatory systems change during development.

\section{$P K C$ and $P C$}

In spite of numerous investigations, the cellular mechanisms responsible for PC have not been fully determined. A number of neuroendocrine and paracrine triggers have been identified, including cathecholamines, bradykinin, adenosine, opioids, endothelin, and angiotensin II ${ }^{26}$ These triggers are coupled through G-proteins to phospholipase $\mathrm{C}$, and the diacylglycerol formed by phospholipase $\mathrm{C}$ activates PKC. Kitakaze et al hypothesized that PC directly activates PKC and the activated PKC phosphorylates ecto5 '-nucleotidase, leading to adenosine production and thereby causing cardioprotection.7 Furthermore, PKC activates mitochondrial KATP channels, which mediate some of the beneficial effects of PC ${ }^{28}$ Therefore, $\mathrm{PKC}$ is thought to be an important mediator in the signal cascade of PC in several animal species including rats.,10-12 $\mathrm{PC}$ is blocked by specific PKC inhibitors and also simulated by direct activation of PKC with a diacylglycerol analogue or $\mathrm{PMA}^{8-12}$ and recent studies have attempted to determine the specific $\mathrm{PKC}$ isoforms that may be responsible for PC.

Yoshida et al demonstrated translocation of the PKCa, $\delta$, and $\epsilon$ isoforms to the membrane fraction during PC in adult rat whole heart, and also showed that a highly specific PKC inhibitor, chelerythrine, inhibits both the improvement of contractile dysfunction during reperfusion and the translocation of PKCa, $\delta$, and $€$ by PC $2^{9}$ They suggested that any of these $3 \mathrm{PKC}$ isoforms can mediate the PC effect. Additionally, they demonstrated that $1 \mu \mathrm{mol} / \mathrm{L}$ PMA treatment can induce translocation of the PKCa, $\delta$, and $\epsilon$ isoforms. Although the experimental preparation and PC procedure in their study were different from ours, the result that only PKC $\delta$ translocated after $100 \mathrm{nmol} / \mathrm{L}$ PMA treatment shown in the present study seems to be inconsistent and may result from the lesser concentration and shorter duration of PMA treatment used in our study.

In the setting of hypoxia or pharmacological preconditioning by phorbol esters, PKCa, $\delta$, and $€$ translocated in both intact rat hearts and isolated cardiomyocytes, suggesting that these 3 isoforms might participate in $\mathrm{PC}^{20,21} \mathrm{In}$ particular, PKC $\delta$ is reported to act through a different pathway than the other isoforms, ${ }^{11,19,21,29}$ supporting the hypothesis that activated PKC $\delta$ plays a pivotal role in PC!1,30 Our study also showed an association between the beneficial effects of PC against ischemic injury and PKC $\delta$ in young-adult rat ventricular cardiomyocytes. Therefore, the decreased expression and translocation of PKC $\delta$ in older rats seen in the present study might explain the impaired tolerance to an ischemic insult and less efficacious $\mathrm{PC}$ in aged rats. ${ }^{13-15}$

\section{Study Limitations and Future Directions}

PC is a complicated, multifactorial phenomenon and the effect of aging on PC may not be solely explained by differences in PKC isoform expression and translocation. Studies are necessary to elucidate the effect of aging on $\mathrm{PC}$, for instance, in transgenic animals or using an isoformspecific activator of PKC, or on the downstream pathways of PKC (especially PKC $\delta$ ) activation. In vivo, interactions with other cell types, including fibroblasts and endothelial cells, and the effects of the autonomic nervous system and hormones cannot be ignored and remain unknown.

In conclusion, we found age-related changes in PKC isoform expression and activation in ventricular cardiomyocytes, which may play a role in the impairment of ischemic tolerance and less efficacious preconditioning that accompanies aging.

\section{Acknowledgments}

This study was supported, in part, by a grant from the Keio Health 
Counseling Center and a Grant-in-Aid for Scientific Research (c), from the Ministry of Education, Science, Sports and Culture, Japan.

We appreciate the advice, suggestions and discussions of our colleagues, Drs. Ken Shinmura, Hiroshi Hasegawa, Ken Yamamura, and Yukako Honma. We also thank Ms. Kayoko Tamaki for her expert technical assistance.

\section{References}

1. Bayer AJ, Chadha JS, Farag RR, Pathy MS: Changing presentations of myocardial infarction with increasing old age. J Am Geriatr Soc 1986; 34: 263-266

2. Keller NM, Feit F: Atherosclerotic heart disease in the elderly. Curr Opin Cardiol 1995; 10: 427-433

3. Wei JY: Age and the cardiovascular system. N Engl J Med 1992; 327: $1735-1739$

4. Pearson AC, Gudipati CV, Labovitz AJ: Effects of aging on left ventricular structure and function. Am Heart J 1991; 121: 871-875

5. Murry CE, Jennings RB, Reimer KA: Preconditioning with ischemia: A delay of lethal cell injury in ischemic myocardium. Circulation 1986; 74: $1124-1136$

6. Hale SL, Kloner RA: Protection of myocardium by transient, preischemic administration of phenylephrine in the rabbit. Coron Artery Dis 1994; 5: 605-610

7. Shizukuda Y, Mallet RT, Lee SC, Downey HF: Hypoxic preconditioning of ischaemic canine myocardium. Cardiovasc Res 1992; 26: $534-542$

8. Speechly-Dick ME, Mocanu MM, Yellon DM: Protein kinase C: Its role in ischemic preconditioning in the rat. Circ Res 1994; 75: 586590

9. Ytrehus K, Liu Y, Downey JM: Preconditioning protects ischemic rabbit heart by protein kinase C activation. Am J Physiol 1994; 266: H1145-H1152

10. Li Y, Kloner RA: Does protein kinase $\mathrm{C}$ play a role in ischemic preconditioning in rat hearts? Am J Physiol 1995; 268: H426-H431

11. Mitchell MB, Meng X, Ao L, Brown JM, Harken AH, Banerjee A: Preconditioning of isolated rat heart is mediated by protein kinase $\mathrm{C}$. Circ Res 1995; 76: 73-81

12. Cave AC, Apstein CS: Polymyxin B, a protein kinase C inhibitor, abolishes preconditioning-induced protection against contractile dysfunction in the isolated blood perfused rat heart. $\mathrm{J} \mathrm{Mol} \mathrm{Cell}$ Cardiol 1996; 28: 977-987

13. Tani M, Suganuma Y, Hasegawa H, Shinmura K, Ebihara Y, Hayashi $Y$, et al: Decrease in ischemic tolerance with aging in isolated perfused Fischer 344 rat hearts: Relation to increases in intracellular $\mathrm{Na}^{+}$after ischemia. J Mol Cell Cardiol 1997; 29: 3081-3089

14. Tani M, Suganuma Y, Hasegawa H, Shinmura K, Hayashi Y, Guo X, et al: Changes in ischemic tolerance and effects of ischemic preconditioning in middle-aged rat hearts. Circulation 1997; 95: 2559-
2566

15. Abete P, Ferrara N, Cioppa A, Ferrara P, Bianco S, Calabrese C, et al: Preconditioning does not prevent postischemic dysfunction in aging heart. J Am Coll Cardiol 1996; 27: 1777-1786

16. Ebihara $Y$, Karmazyn M: Inhibition of $\beta$ but nota 1 -mediated adrenergic responses in isolated hearts and cardiomyocytes by nitric oxide and 8-bromo cyclic GMP. Cardiovasc Res 1996; 32: 622-629

17. Clerk A, Bogoyevitch MA, Fuller SJ, Lazou A, Parker PJ, Sugden $\mathrm{PH}$ : Expression of protein kinase $\mathrm{C}$ isoforms during cardiac ventricular development. Am J Physiol 1995; 269: H1087-H1097

18. Erdbrügger W, Keffel J, Knocks M, Otto T, Philipp T, Michel MC: Protein kinase $\mathrm{C}$ isoenzymes in rat and human cardiovascular tissues. Br J Pharmacol 1997; 120: 177-186

19. Pucéat M, Hilal-Dandan R, Strulovici B, Brunton LL, Brown JH: Differential regulation of protein kinase $\mathrm{C}$ isoforms in isolated neonatal and adult rat cardiomyocytes. J Biol Chem 1994; 269: $16938-16944$

20. Albert CJ, Ford DA: Protein kinase $\mathrm{C}$ translocation and PKC-dependent protein phosphorylation during myocardial ischemia. Am $J$ Physiol 1999; 276: H642-H650

21. Goldberg M, Zhang HL, Steinberg SF: Hypoxia alters the subcellular distribution of protein kinase $\mathrm{C}$ isoforms in neonatal rat ventricular myocytes. J Clin Invest 1997; 99: 55-61

22. Kohout TA, Rogers TB: Use of a PCR-based method to characterize protein kinase C isoform expression in cardiac cells. Am J Physiol 1993; 264: C1350-C1359

23. Rybin VO, Steinberg SF: Protein kinase $C$ isoform expression and regulation in the developing rat heart. Circ Res 1994; 74: 299-309

24. Rybin VO, Steinberg SF: Do adult rat ventricular myocytes express protein kinase Ca? Am J Physiol 1997; 272: H2485-H2491

25. Rogue PJ, Ritz MF, Malviya AN: Impaired gene transcription and nuclear protein kinase $\mathrm{C}$ activation in the brain and liver of aged rats. FEBS Lett 1993; 334: 351-354

26. Yellon DM, Baxter GF, Garcia-Dorado D, Heusch G, Sumeray MS: Ischaemic preconditioning: Present position and future directions. Cardiovasc Res 1998; 37: 21-33

27. Kitakaze M, Minamino T, Node K, Takashima S, Funaya H, Kuzuya $\mathrm{T}$, et al: Adenosine and cardioprotection in the diseased heart. Jpn Circ J 1999; 63: 231-243

28. Sato T, O'Rourke B, Márban E: Modulation of mitochondrial ATPdependent $\mathrm{K}^{+}$channels by protein kinase C. Circ Res 1998; 83: 110_ 114

29. Yoshida K, Kawamura S, Mizukami Y, Kitakaze M: Implication of protein kinase $\mathrm{Ca}, \delta$ and $\epsilon$ isoforms in ischemic preconditioning in perfused rat hearts. J Biochem (Tokyo) 1997; 122: 506-511

30. Zhao J, Renner O, Wightman L, Sugden PH, Stewart L, Miller AD, et al: The expression of constitutively active isotypes of protein kinase C to investigate preconditioning. J Biol Chem 1998; 273: 23072-23079 